\title{
Bisphosphonates enhance EGFR-TKIs efficacy in advanced NSCLC patients with EGFR activating mutation: A retrospective study
}

\author{
Chu-Ying Huang ${ }^{1,3, *}$, Li Wang ${ }^{1,4, *}$, Cheng-Jun Feng ${ }^{1, *}$, Ping Yu${ }^{2, *}$, Xiao-Hong Cai ${ }^{2}$, \\ Wen-Xiu Yao ${ }^{2}$, Yong Xu' ${ }^{1}$, Xiao-Ke Liu ${ }^{1}$, Wen-Jiang Zhu ${ }^{1}$, Yan Wang ${ }^{1,5}$, Jin Zhou ${ }^{2}$, \\ You Lu' ${ }^{1}$, Yong-Sheng Wang ${ }^{1}$ \\ ${ }^{1}$ Department of Thoracic Oncology, Cancer Center, and State Key Laboratory of Biotherapy/Collaborative Innovation Center \\ of Biotherapy, West China Hospital, Sichuan University, Chengdu, China \\ ${ }^{2}$ Department of Oncology, The Second People's Hospital of Sichuan, Chengdu, China \\ ${ }^{3}$ Department of Medical Oncology, Enshi Tujia and Miao Autonomous Prefecture Central Hospital, Hubei Province, China \\ ${ }^{4}$ Department of Dermatology, Enshi Tujia and Miao Autonomous Prefecture Central Hospital, Hubei Province, China \\ ${ }^{5}$ Department of Oncology, The First People's Hospital of Longquanyi District, Chengdu, China \\ *These authors have contributed equally to this work \\ Correspondence to: Yong-Sheng Wang, email: wangys@scu.edu.cn,wangys75@gmail.com \\ Keywords: bisphosphonates, EGFR-TKIs, NSCLC, EGFR mutations, bone metastases \\ Received: April 30, 2015 \\ Accepted: September 05, 2015 \\ Published: November 27, 2015
}

\section{ABSTRACT}

Background: Bisphosphonates have exhibited anti-tumor activity in nonsmall cell lung cancer (NSCLC). We aimed to evaluate whether the combination of bisphosphonates with tyrosine kinase inhibitors of EGFR (EGFR-TKIs) could obtain a synergistic effect on advanced NSCLC patients with EGFR mutations.

Methods: Between January 2008 and October 2013, 114 advanced EGFR mutations NSCLC patients who received EGFR-TKIs as first-line therapy were recruited from two cancer centers. Patients were separated into EGFR-TKIs alone or EGFR-TKIs plus bisphosphonates (combination) group. Median progression free survival (mPFS), median overall survival (mOS) distributions and survival curves were analyzed.

Results: Among the 114 patients, 62 had bone metastases (19 patients treated with EGFR-TKIs, 43 patients treated with EGFR-TKIs + bisphosphonates). Median PFS and $O S$ were significantly improved in combination group compared with EGFR-TKIs group (mPFS: 15.0 vs 7.3 months, $P=0.0017$; mOS: 25.2 vs 10.4 months, $P=0.0015$ ) in patients with bone metastases. Among the 71 patients (19 patients with bone metastases) treated with EGFR-TKIs alone, patients with bone metastases had poor survival prognosis (mPFS:7.3 vs 12.1 months, $P=0.0434 ;$ mOS:10.4 vs 22.0 months, $P=0.0036$ ). The survival of patients with bone metastases who received EGFR-TKIs plus bisphosphonates therapy was non-inferior to patients without bone metastases treated with EGFR-TKIs alone (mPFS: 15.0 vs 12.1 months, $p=0.1871$; mOS: 25.2 vs 22.0 months, $p=0.9798$ ).

Conclusions: Concomitant use of bisphosphonates and EGFR-TKIs improves therapeutic efficacy and brings survival benefits to NSCLC patients with EGFR mutation and bone metastases. 


\section{INTRODUCTION}

Lung cancer is the most common cancer worldwide [1]. Non-small-cell lung cancer (NSCLC) accounts for $85 \%$ of lung cancer and is often diagnosed at an advanced stage (inoperable stage IIIB or stage IV). For patients with advanced lung cancer, the incidences of bone metastases at diagnosis and at follow-up are approximately $30 \%$ $40 \%$. Median overall survival time is $<6$ months and the 5 -year survival rate is $<5 \%$ [2]. Bone metastases may lead to skeletal-related events (SREs) such as bone pain, hypercalcemia, spinal cord compression, and pathologic fractures. Median survival time after the first SREs in patients with advanced lung cancer with bone metastases is only 4.1 months and SREs tend to have worse survival $[3,4]$.

Bisphosphonates are stable analogues of inorganic pyrophosphate that induce osteoclast apoptosis, inhibit bone resorption, osteoclast formation and recruitment [5]. Among the new-generation bisphosphonates, Zoledronic acid is efficient for the prevention of skeletal complications and generally recommended in patients with symptomatic bone metastases. Recently, preclinical data have shown that zoledronic acid might exert anti-tumor effects in NSCLC, including the inhibition of tumor cell proliferation, invasion, angiogenesis, and micrometastasis [6-10]. Clinical data also suggest that bisphosphonates may exhibit anti-tumor activity and prevent tumor progression of NSCLC $[11,12]$.

EGFR mutation is observed in $10 \%$ of the European NSCLC patients, and it is as high as $30-40 \%$ in East Asian patients. The objective response rate is about $71.2 \%$ when treated with EGFR-TKIs as the first-line therapy for the EGFR mutation advanced NSCLC [13], and the survival of patients with EGFR mutation is similar with EGFR wild type patients [14]. A retrospective clinical study found that the incidence of bone metastasis was similar in NSCLC patients with EGFR mutations compared to EGFR wild type patients [15]. Therefore, EGFR mutation NSCLC patients in the course of disease with bone metastasis are very common. Clinically, those patients with bone metastases and EGFR sensitive mutation of NSCLC, often used bisphosphonates and EGFR-TKIs concomitantly. However, whether the treatment effects could be improved by combination with bisphosphonates and EGFR-TKIs in these patients is still unknown. Two retrospective studies indicated that bisphosphonates combined with sunitinib/ sorafenib could improve the response rate, PFS and OS in renal cell carcinoma with bone metastases $[16,17]$, which suggested that the combination of bisphosphonates and EGFR-TKIs probably also bring benefits to NSCLC. In the present study, we aimed to assess whether bisphosphonates can bring survival benefits to advanced NSCLC patients with bone metastases and treated with EGFR-TKIs.

\section{RESULTS}

\section{Patient characteristics}

One hundred and fourteen patients (mean \pm SD: $59.05 \pm 11.2$, range $36-85$, male $43.9 \%$ ) with metastatic NSCLC (stage IV) received EGFR-TKIs as first-line treatment between 1st January 2008 and 31st October 2013 were included in this study. All patients harboring EGFR activating mutations were confirmed by ARMSPCR or sequencing. In 114 patients, $73(64.0 \%)$ were 19-del mutation and $41(36.0 \%)$ were L858R mutation. The number of patients receiving gefitinib, erlotinib and icotinib treatment was 81,16 and 17 , respectively. In these 114 patients, 62 patients had bone metastases. Among these 62 patients, 43 were bisphosphonates users and 19 were nonusers due to oligo, small and asymptomatic bone metastases. In another 52 patients without bone metastases patients, none of them received bisphosphonates. Those patients who have received bisphosphonates, 35 were treated with zoledronic acid (4 mg monthly) and 8 with pamidronate ( $90 \mathrm{mg}$ monthly). Therefore, among all the 114 patients, 71 were treated with EGFR-TKIs alone and 43 with EGFR-TKIs plus bisphosphonates. During EGFRTKI treatment period, there was no one SREs occurrence in EGFR-TKIs alone group. In all patients, 109 had adenocarcinoma histology, 5 patients had squamous cell carcinoma. Nine of $114(7.9 \%)$ patients had postoperative recurrent disease. All the distributions of clinic-pathologic characteristics were well balanced between the two treatment groups and were shown in Table 1.

\section{EGFR-TKIs and bisphosphonates treatment efficacy}

Median follow-up time was 12 months (mean $\pm \mathrm{SD}$ : $14 \pm 8.6$, range 1-72). All patients completed the treatment successfully, and none of them withdrew the treatment due to unacceptable adverse effects. Firstly, we investigated the effects of Bisphosphonates on these patients with both EGFR activating mutation and bone metastases. Among the 114 patients, 62 patients with bone metastases received EGFR-TKIs or EGFR-TKIs plus bisphosphonates as first-line therapy (19 patients treated with EGFRTKIs alone, 43 patients treated with EGFR-TKIs plus bisphosphonates). The results showed that median PFS was significantly improved in the combination group compared to the EGFR-TKIs alone group (15.0 vs 7.3 months; HR 2.500, 95\% CI: 2.022 to $2.978, p=0.0017$, Figure 1). Median OS was also significantly longer in the combination group than in the EGFR-TKIs alone group (25.2 vs 10.4 months; HR $2.143,95 \%$ CI: 1.670 to $2.616, p=0.00015$, Figure 2). Therefore, among those patients with bone metastases, treatment with EGFR-TKIs plus bisphosphonates had superior efficacy compared to EGFR-TKIs treatment alone. 
Table 1: Patient characteristics
Patient characteristics
Only TKI $(n=52)$
TKI +BPs $(n=43)$
TKI alone(with bone
metastases, $n=19$ )

\begin{tabular}{|c|c|c|c|}
\hline \multicolumn{4}{|l|}{ Age-(year) } \\
\hline Mean & 59 & 59.2 & 58.6 \\
\hline Rang & $38-85$ & $36-81$ & $38-85$ \\
\hline \multicolumn{4}{|l|}{ Sex } \\
\hline Male & 21 & 20 & 9 \\
\hline Fenale & 31 & 23 & 10 \\
\hline \multicolumn{4}{|l|}{ Histologic feature of tumor } \\
\hline Adenocarcinoma & 49 & 43 & 17 \\
\hline Squamas cell & 3 & 0 & 2 \\
\hline \multicolumn{4}{|l|}{ EGFR statue } \\
\hline L858R & 17 & 16 & 8 \\
\hline 19DEL & 35 & 27 & 11 \\
\hline \multicolumn{4}{|l|}{ Disease stage } \\
\hline IV & 52 & 43 & 19 \\
\hline \multicolumn{4}{|c|}{ Time from diagnosis to start of TKI } \\
\hline$<6 \mathrm{mo}$ & 50 & 39 & 18 \\
\hline$\geq 6 \mathrm{mo}$ & 2 & 4 & 1 \\
\hline \multicolumn{4}{|l|}{ Site of metastasis } \\
\hline Brain & 11 & 11 & 6 \\
\hline Liver & 1 & 2 & 0 \\
\hline Bone & 0 & 43 & 19 \\
\hline Sites of metastases $\geq 3$ & 0 & 17 & 7 \\
\hline Suprarenal gland & 3 & 3 & 2 \\
\hline \multicolumn{4}{|c|}{ Patient characteristics at start of TKI } \\
\hline \multicolumn{4}{|l|}{ WHO performance status } \\
\hline $0-1$ & 52 & 43 & 18 \\
\hline $2-3$ & 0 & 0 & 1 \\
\hline $\mathrm{WC}<3.5 \times 109$ & 2 & 2 & 1 \\
\hline Neutrophils <2 X 109 & 1 & 1 & 0 \\
\hline Platelets $<100$ X 109 & 4 & 2 & 0 \\
\hline $\begin{array}{l}\text { Haemoglobin }<11.5 \mathrm{~g} / \\
\mathrm{dl}(\text { woman }),<13 \mathrm{~g} / \mathrm{dl}(\mathrm{man})\end{array}$ & 16 & 16 & 9 \\
\hline LDH41.5x ULN & 24 & 20 & 5 \\
\hline ALP & 1 & 16 & 4 \\
\hline
\end{tabular}

Next, we compared the effect of EGFR-TKIs treatment alone on those patients with or without bone metastases. In 71 patients treated with EGFR-TKIs alone, there were 19 patients with bone metastases. The
19 patients received EGFR-TKIs treatment alone due to oligo and small bone metastases and without symptoms associated with bone metastases. Those patients finally did not suffer from SREs. However, those patients with bone 
metastases had worse survival (mPFS: 7.3 vs 12.1 months, $P=0.0434$; mOS: 10.4 vs 22.0 months, $P=0.0036$, Figure 3,4 ), indicating bone metastases brought adverse effects and was a predictor for poor prognosis.

Subsequently, we compared the effect of EGFR-TKIs plus bisphosphonates to EGFR-TKIs alone treatment on those patients with or without bone metastases, respectively. Interestingly, among the 114 patients, 52 patients without bone metastases treated with EGFR-TKIs alone, 43 patients with bone metastases treated with EGFR-TKIs plus bisphosphonates as first-line therapy, median PFS time was 15.0 months in the EGFR-TKIs plus bisphosphonates group and 12.1 months in the EGFR-TKIs group (HR 1.250; 95\% CI: 0.7358 to $1.764 ; p=0.1871$; Figure 5). Median OS time was 25.2 months in combination group and 22.0 months in EGFR-TKIs alone group (HR 1.136; 95\% CI, 0.6166 to $1.656, p=0.9798$, Figure 6$)$. The results suggested bisphosphonates treatment actually antagonized the adverse effects resulted from bone metastases.

In addition, the proportion of the 114 patients who responded during the treatment period (the best overall response of $\mathrm{CR}, \mathrm{PR}$, or $\mathrm{SD}$ ) in the EGFR-TKIs alone group was lower than combination group (80.28\% vs $90.69 \%, P=0.299)$, but the difference was not statistically significant.

\section{Univariate analysis of factors associated with PFS and OS}

Table 2 gives an overview of all previously described prognostic factors assessed by univariate analysis. The results showed that baseline hemoglobin (Hb) was associated with PFS $(p=0.012)$ and OS $(p=0.005)$. The $\mathrm{Hb}$ and alkaline phosphatase (ALP) in mPFS and mOS univariate analysis with a $P$-value $<0.2$ were included in multivariate model (Cox regression) to determine their independent effects.

\section{Multivariate analysis of factors associated with PFS and OS}

In multivariate analysis (Table 3), bisphosphonate administration, baseline hemoglobin and baseline alkaline phosphatase were independently linked to PFS and OS.

\section{Drug toxicity}

Adverse events occurring in the treatment groups were listed in Table 4. All adverse events shown in Table 4 are acceptable. The most common adverse events in EGFR-TKIs group were skin rash followed by diarrhea, cutaneous pruritus and dry skin. By contrast, the most common adverse events in EGFR-TKIs plus bisphosphonates group were skin rash, cutaneous pruritus, diarrhea and liver dysfunction. There was no occurrence of jaw osteonecrosis. Our findings suggest that the combined treatment of EGFR-TKIs and bisphosphonates does not increase the side effects of EGFR-TKIs.

\section{DISCUSSION}

Lung cancer is the most common cancer worldwide [1] and approximately $30 \%-40 \%$ patients with advanced NSCLC develop bone metastases [2]. Bisphosphonates are the most commonly used for the treatment of skeletal complications associated with bone metastases and have been proven to significantly delay the median time to first SRE and reduce the risk of skeletal complications among patients with bone metastases from lung cancer and other solid tumors $[11,18,19]$. In addition to the

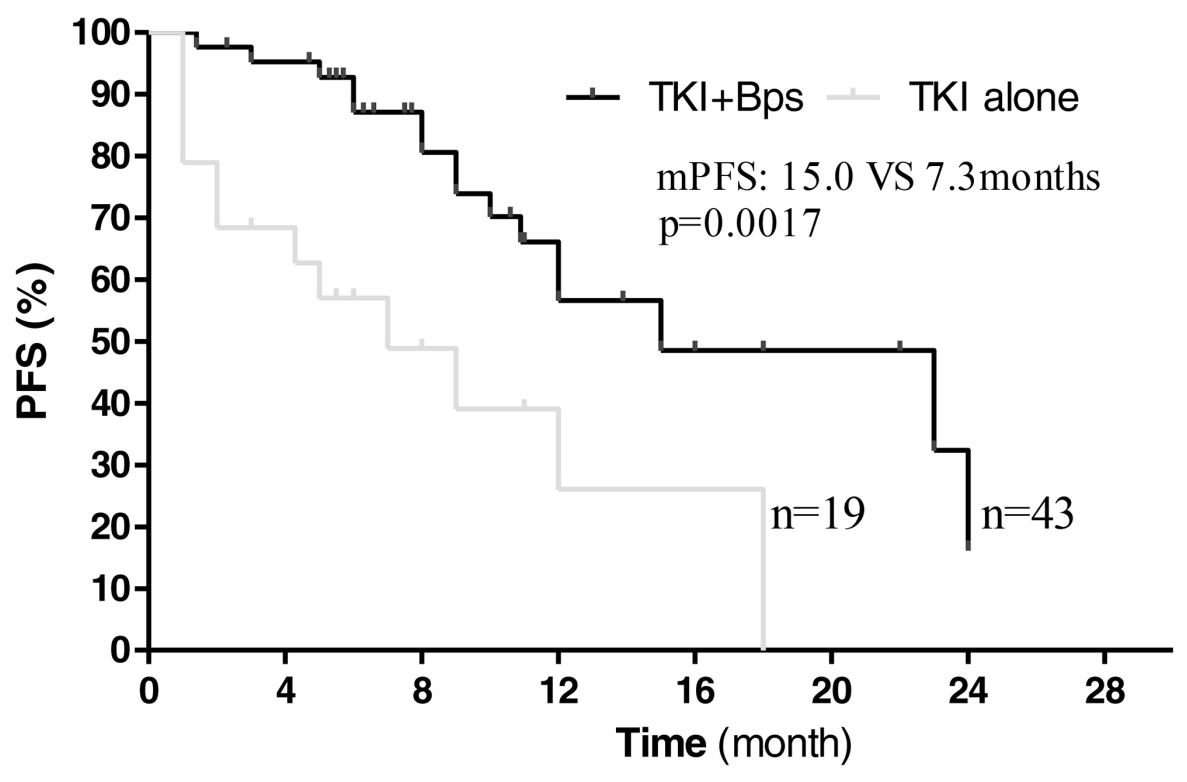

Figure 1: Kaplan-Meier curves showing progression-free survival, stratified by the use of bisphosphonates. 
established SRE-prevention benefits, previous clinical studies also suggested that bisphosphonates therapy could provide survival benefits to NSCLC and other tumors patients with bone metastases [20-22]. Here, our investigation showed the effects of treatment with EGFR-TKIs plus bisphosphonates were better than EGFR-TKIs alone in those NSCLC patients with EGFR mutation and bone metastases. Among 62 patients with bone metastases, 19 patients were treated with EGFRTKIs alone due to oligo, small and asymptomatic bone metastases. PFS and OS were significantly improved in the EGFR-TKIs plus bisphosphonates group compared with the EGFR-TKIs group. Multivariate analysis also showed bisphosphonate administration associated with improved PFS and OS. Therefore, for patients with single, small or asymptomatic metastatic bone lesions, our study supported bisphosphonates therapy should be used as early as possible.

During the EGFR-TKIs treatment course, there was no SREs occurrence in those patients with bone metastases. Therefore, we speculated that the prolonged PFS and OS with EGFR-TKIs plus Bisphosphonates treatment did not result from SRE-prevention benefits of bisphosphonates. Currently, serial preclinical studies

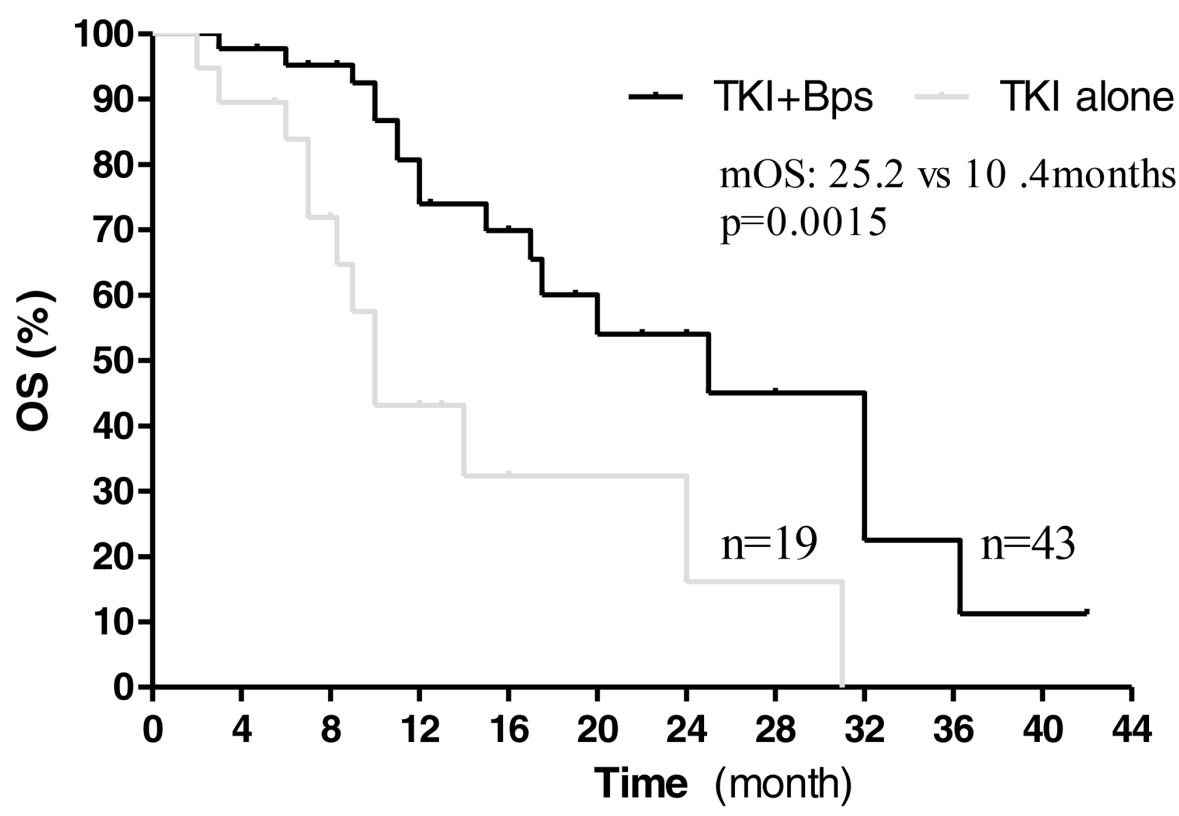

Figure 2: Kaplan-Meier curves showing overall survival, stratified by the use of bisphosphonates.

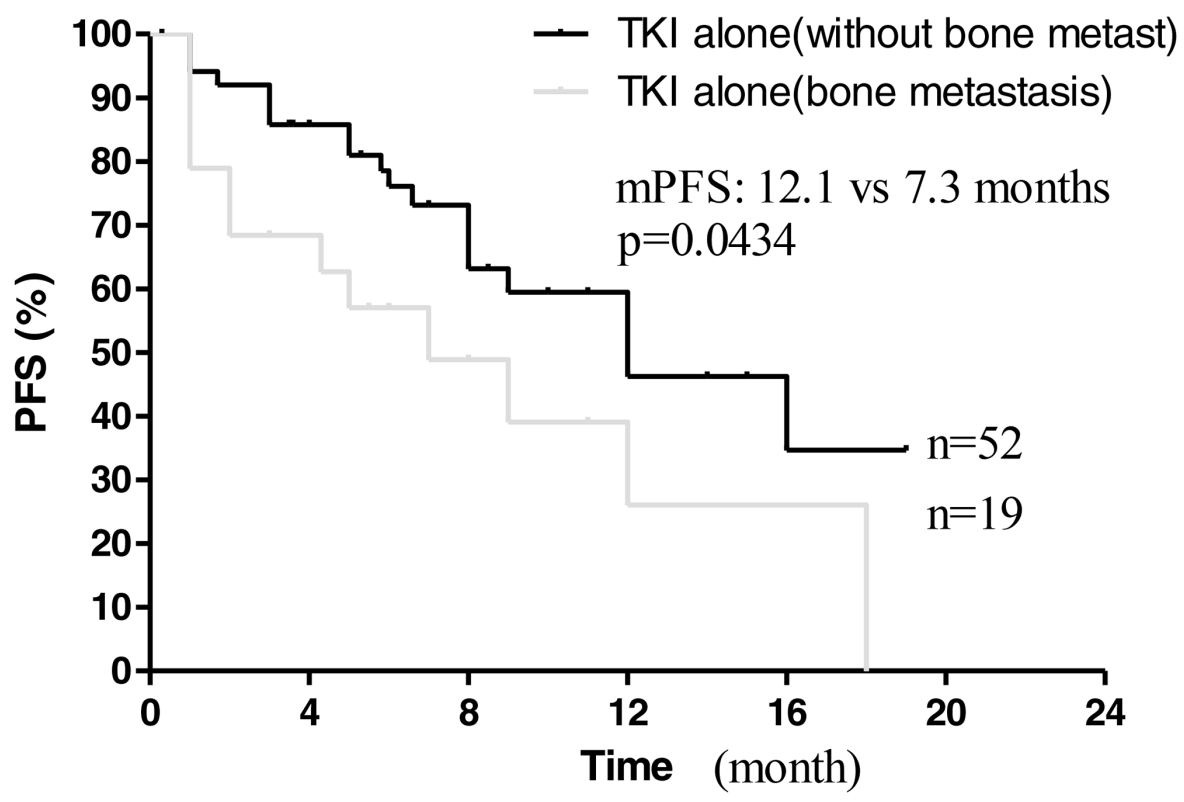

Figure 3: Kaplan-Meier curves for progression-free survival are shown for patients with bone metastases. 
have confirmed that bisphosphonates have direct antitumor effects on a variety of tumors, including NSCLC [23-25]. The mechanism includes regulating cell cycle, inducing tumor cells apoptosis, inhibiting tumor cell invasion and metastasis, affecting tumors molecular signal pathways, regulating immune microenvironment and anti-angiogenesis [24-29]. However, there are two researches studied whether bisphosphonates treatment NSCLC without bone metastasis could improve survival $[30,31]$. One randomized, phase III study evaluated whether zoledronic acid could delay disease progression or recurrence in patients with controlled stage IIIA/B NSCLC after first-line therapy [30]. Another randomized, phase 2 study evaluated the ability of zoledronic acid to augment the cytotoxic effects of the combination of docetaxel/carboplatin and to delay disease progression in patients with inoperable stage IIIB or IV NSCLC [31]. In those two studies, zoledronic acid treatment did not improve the survival. Furthermore, even in a clinical trial in NSCLC patients with bone metastases, the combination of bisphosphonates and docetaxel also failed to improve the survival when compared with docetaxel alone [32]. These investigations suggested that clinical effects of bisphosphonates treatment alone or combining with chemotherapy on NSCLC patients are limited.

Two preclinical studies showed that combined treatment with gefitinib and zoledronic acid produced a tumor-suppressing effect significantly, which was more

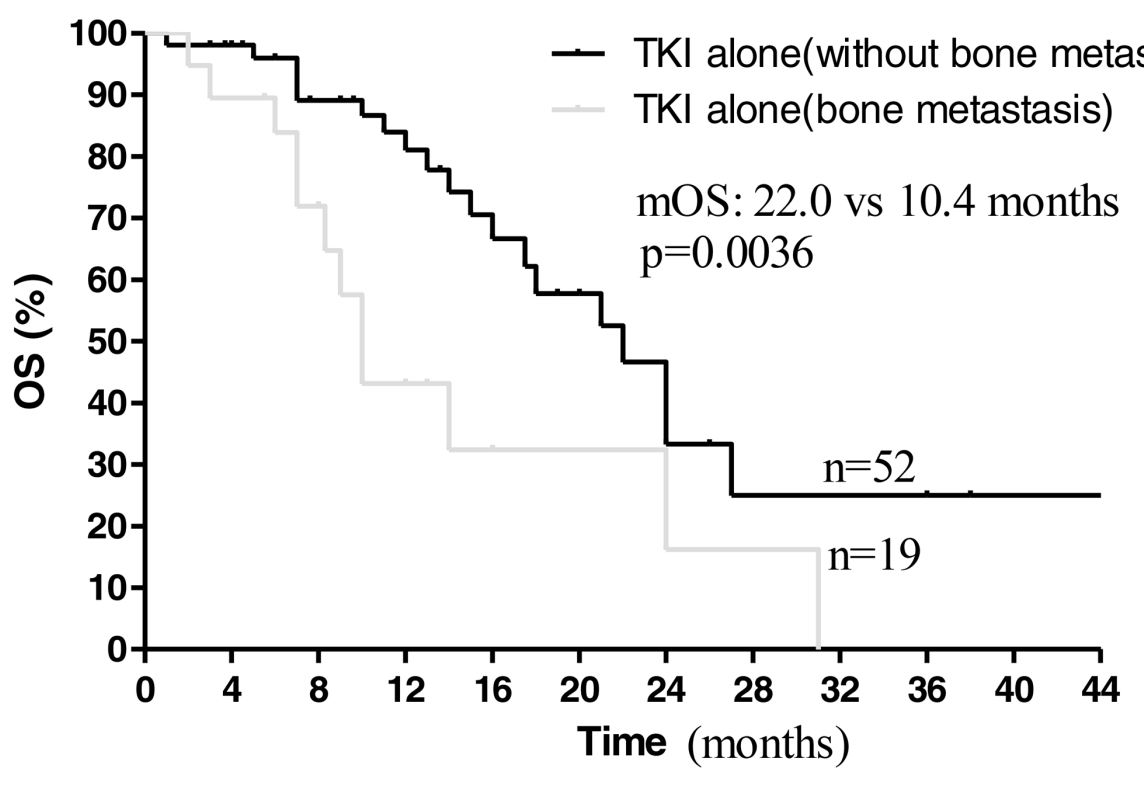

Figure 4: Kaplan-Meier curves for overall survival are shown for patients with bone metastases.

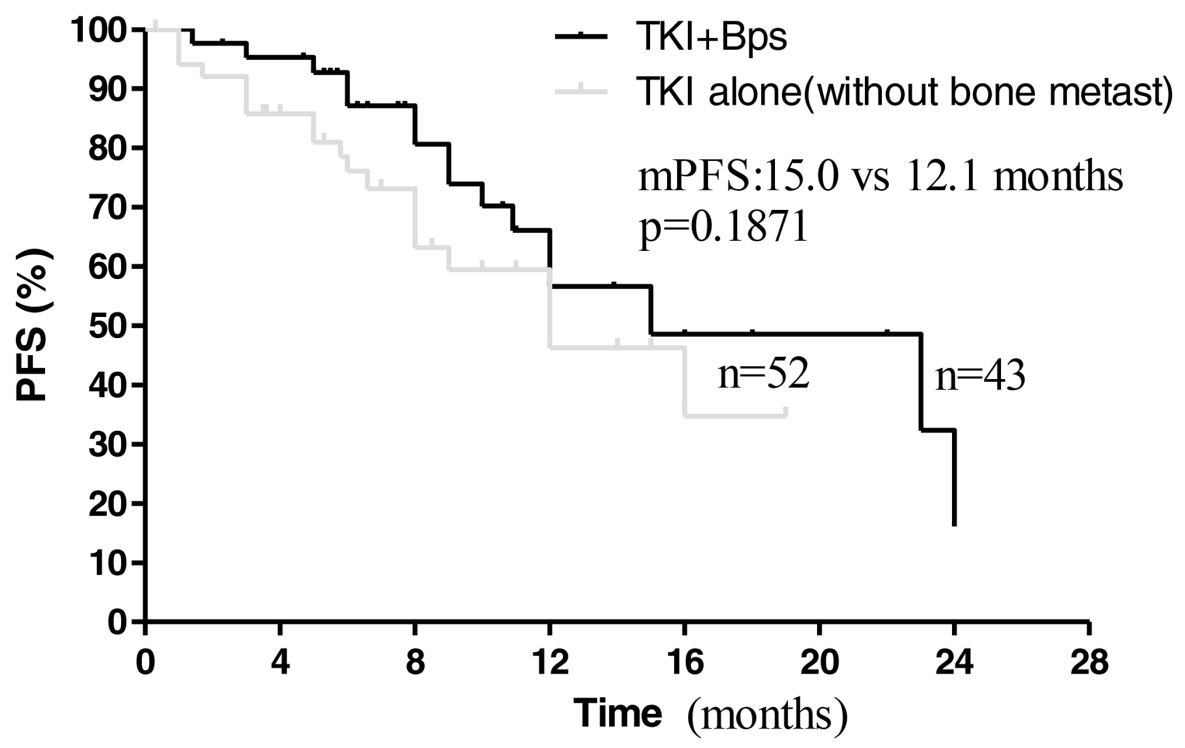

Figure 5: Kaplan-Meier curves for progression-free survival are shown for patients without bone metastases treated with TKI alone and patients treated with TKI+BPs. 
effective than the individual antitumor effect of gefitinib or zoledronic acid in vitro and in vivo [10,33]. One study showed that gefitinib could inhibit ERK1/2 and Akt protein phosphorylation, result in tumor cells arrest in G1 phase and induce apoptosis [10]. Zoledronic acid could not only inhibit ERK $1 / 2$ and Akt activating in NSCLC, but it also could inhibit STAT3 activating in other tumors. Another study showed that zoledronic acid plus gefitinib could synergistically inhibit ERK1/2, Akt and STAT3 activating, which were the major signaling pathways of EGFR [33]. As known, re-activations of Akt and STAT have proven to be important for EGFRTKIs resistance [34, 35]. The effects of bisphosphonates on downstream signaling of EGFR might bring potential clinical benefits for NSCLC patients with EGFR mutation and who received EGFR-TKIs treatment. In this study, our data revealed that EGFR-TKIs plus bisphosphonates indeed prolonged PFS and OS in EGFR mutation NSCLC patients who received EGFR-TKIs as the first-line therapy. There was other clinical evidence of survival benefits treated with bisphosphonates and EGFR-TKIs in some malignancies with bone metastases $[16,17]$. A multicentre retrospective study indicated that bisphosphonates combined with sunitinib improved the response rate, PFS and OS in renal cell carcinoma with bone metastases [16]. Another retrospective study of 76 patients with metastatic renal cell carcinoma revealed that concomitant use of bisphosphonates and EGFR-TKIs in renal cell carcinoma patients with bone metastases probably improved treatment efficacy [17]. Therefore, we considered that bisphosphonates actually could enhance, even sensitize the effects of EGFR-TKIs on NSCLC patients with EGFR mutation. The effects of bisphosphonates on signaling of EGFR-TKIs resistance are speculated to be different from chemotherapy resistance, this may account for the enhanced antitumor effects and prolonged PFS and OS.

Our findings also showed that bone metastasis was an independent predictor of poor prognosis for advanced NSCLC patients with EGFR mutations received EGFR-TKIs treatment. Among these patients treated with EGFR-TKIs alone, significant difference of PFS and OS was observed between with and without bone metastases (Figure 3 and 4). Multivariate analysis also showed ALP associated with PFS and OS. As known, ALP level is closely related to malignant tumor with bone metastases $[16,17]$. On the other hand, there was no prognostic difference observed between NSCLC patients with bone metastases received EGFR-TKIs plus bisphosphonates and those without bone metastasis treated with EGFR-TKIs alone (Figure 5,6). This suggested that bisphosphonates treatment actually countered the adverse effects from bone metastases and brought survival benefits in EGFR mutation NSCLC patients with bone metastases. So far, there are no clinical data to answer whether bisphosphonates could enhance the effects of EGFR-TKIs in EGFR mutation patients without bone metastases. Our data may support further pre-clinical and clinical investigations.

We have to admit that our study has some limitations. First, in this retrospective clinical study, we are unable to exclude all the possibility of unequal distribution of unidentified clinic-pathologic parameters in each group. In addition, the number of cases in each group is relatively small, which might bias the results. Second, percentage of EGFR 19-del mutation (64\%) is higher than L858R mutation in exon 21 (36\%) in this study. As we know, 19-del mutation and L858R mutation each accounts for about $40-45 \%$ in all EGFR mutations of NSCLC [36,

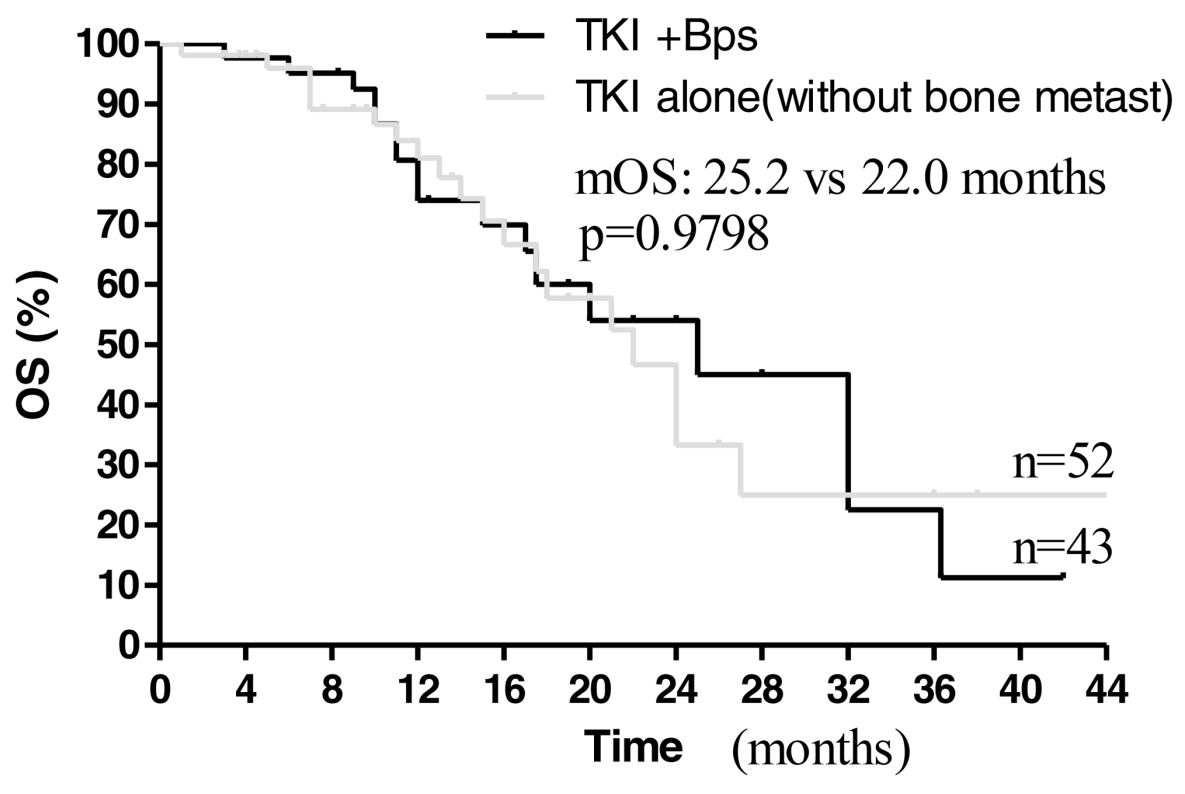

Figure 6: Kaplan-Meier curves for overall survival are shown for patients without bone metastases treated with TKI alone and patients treated with TKI+BPs. 
Table 2: Univariate analysis

\begin{tabular}{|c|c|c|c|c|}
\hline $\begin{array}{l}\text { Parameter (number } \\
\text { of patients) }\end{array}$ & Median PFS (month) & $P$ & $\begin{array}{c}\text { Median OS } \\
\text { (month) }\end{array}$ & $P$ \\
\hline Bone metastases(53) & 12 & 0.371 & 21 & 0.761 \\
\hline $\begin{array}{l}\text { No bone } \\
\text { metastases(62) }\end{array}$ & 16 & & 23 & \\
\hline Brain metastases(28) & 16 & 0.39 & 13 & 0.789 \\
\hline $\begin{array}{l}\text { No brain } \\
\text { metastases(86) }\end{array}$ & 12 & & 22 & \\
\hline $\begin{array}{l}\mathrm{Hb}<11.5 \mathrm{~g} / \\
\mathrm{dl}(\text { woman }),<13 \mathrm{~g} / \\
\mathrm{dl}(\operatorname{man})(41)\end{array}$ & 9 & 0.012 & 18 & 0.005 \\
\hline Hb nomal(73) & 16 & & 24 & \\
\hline PLT $<100 \times 10^{\wedge} 9 / \mathrm{L}(10)$ & 10 & 0.807 & 16 & 0.164 \\
\hline PLT nomal(104) & 15 & & 23 & \\
\hline ALP > 160 IU/L(21) & 12 & 0.21 & 15 & 0.134 \\
\hline ALP nomal(93) & 15 & & 24 & \\
\hline LDH > 220 IU/L(49) & 15 & 0.405 & 25 & 0.582 \\
\hline LDH nomal(65) & 12 & & 20 & \\
\hline $\mathrm{WC}>10 \times 10^{\wedge} 9 / \mathrm{L}(13)$ & 12 & 0.397 & 21 & 0.924 \\
\hline WC nomal(101) & 16 & & 23 & \\
\hline Gefetinib(81) & 12 & 0.628 & 22 & 0.272 \\
\hline Erolotinib(16) & 12 & & 20 & \\
\hline Icotinib(17) & 12 & & 21 & \\
\hline 19DEL(73) & 10 & 0.48 & 24 & 0.43 \\
\hline L858R(41) & 10 & & 20 & \\
\hline
\end{tabular}

Table 3: Multivariate analysis

\begin{tabular}{|c|c|c|c|}
\hline & $P$-value & Hazard ratio & $95 \% \mathrm{CI}$ \\
\hline \multicolumn{4}{|l|}{ For PFS } \\
\hline $\begin{array}{l}\text { Bisphosphonate } \\
\text { administration or not }\end{array}$ & 0.002 & 3.955 & $1.65-9.483$ \\
\hline Baseline hemoglobin & 0.037 & 0.515 & $0.275-0.962$ \\
\hline $\begin{array}{l}\text { Baseline alkaline } \\
\text { phosphatase }\end{array}$ & 0.005 & 0.265 & $0.105-0.666$ \\
\hline \multicolumn{4}{|l|}{ For OS } \\
\hline $\begin{array}{l}\text { Bisphosphonate } \\
\text { administration or not }\end{array}$ & 0.004 & 3.566 & $1.489-8.540$ \\
\hline Baseline hemoglobin & 0.005 & 0.379 & $0.192-0.748$ \\
\hline $\begin{array}{l}\text { Baseline alkaline } \\
\text { phosphatase }\end{array}$ & 0.004 & 0.234 & $0.088-0.626$ \\
\hline
\end{tabular}


Table 4: Treatment-related adverse events

Patients with treatment-related
adverse
\begin{tabular}{|l|c|c|}
\hline Rash & 12 & TKI+BPs \\
\hline Pruritus & 2 & 4 \\
\hline dry skin & 1 & 3 \\
\hline Diarrhoea & 2 & 1 \\
\hline
\end{tabular}

37]. Previous study found that, 19-del mutation is more sensitive to EGFR-TKIs compared with L858R mutation $[38,39]$. Therefore, different composing of cases may affect the results. Third, this study included 5 patients with squamous cell carcinoma, they all received EGFRTKIs monotherapy. Previous studies have found that, even with EGFR mutations in squamous cell carcinoma, it is still the inferior efficiency treatment with EGFRTKIs than adenocarcinoma with EGFR mutations [40]. Actually, we analyzed our data and get similar results when excluding the five patients (Supplementary Figure 1-6, S1-S6). Finally, bisphosphonates used in this study were mostly zoledronic acid, while treatment using other bisphosphonates were rare. Therefore, whether other bisphosphonates could improve patients survival combined with EGFR-TKIs needs further investigation.

In summary, our study confirmed that bisphosphonates combined with EGFR-TKIs prolonged PFS and OS of NSCLC patients with EGFR mutations and bone metastases. Our study also suggests bisphosphonates should be given as early as possible to the patients even with oligo bone metastases, and the enhanced effects of bisphosphonates on EGFR-TKIs may deserve to be investigated in further clinical trials.

\section{PATIENTS AND METHODS}

\section{Patient selection}

This was a retrospective study. The primary objective was to assess the impact of concomitant bisphosphonates on progression-free survival (PFS) under treatment with EGFR-TKIs. PFS was defined as the lapse of time between the start of EGFR-TKIs therapy and progressive disease under the targeted therapy or death. The secondary objective was to assess the impact of treatment with bisphosphonates on overall survival (OS) in such patients. OS was defined as the lapse of time between the start of targeted therapy and death of any cause.

One hundred and fourteen metastatic NSCLC patients (stage IV) with EGFR mutations were treated with EGFR-TKIs between 1st January 2008 and 31st October 2013, in two cancer centers (West China Hospital of Sichuan University and the Second People's Hospital of Sichuan, Sichuan province, China). Patients were eligible for inclusion in this study if they were 18 years of age or older, had been diagnosed as advanced NSCLC (stage IV), contained EGFR activating mutation, and received firstline EGFR-TKIs treatment, at least 1 measurable tumor lesions as evaluated by imaging detection. Patients who stopped EGFR-TKIs before completing 4 weeks of EGFRTKIs treatment were excluded.

\section{EGFR-TKIs and bisphosphonates treatment}

All patients received EGFR-TKIs treatment, including Gefitinib, Icotinib and Erlotinib. Treatment was continued until the evidence of disease progression, unacceptable adverse events or death. The decision whether to start bisphosphonates in those with bone metastases NSCLC patients were at the discretion of the treating physician. Bisphosphonates were administrated every 3-4 weeks according to the guidelines. Patients with concomitant bisphosphonates were defined as patients who started bisphosphonates together with EGFR-TKIs or who received them before and until the beginning or during the treatment with first-line EGFR-TKIs.

\section{Disease assessments}

Follow-up time was defined as the time from EGFR-TKIs treatment initiation to 31st October 2013. During the treatment, all patients underwent chest CTscan every 2-3 months. Bone metastases assessments were detected by CT scan, MRI and/or bone scintigraphy. Tumor response was defined according to the Response Evaluation Criteria in Solid Tumors 1.1 (RECIST 1.1) criteria. Treatment associated toxicity was evaluated according to the National Cancer Institute Common Terminology Criteria for Adverse Events (NCI-CTCAE) version 4.0.

\section{Statistical analysis}

Progression-free survival and OS distributions were estimated using the Kaplan-Meier method and survival curves were compared with log-rank test. Univariate and multivariate Cox proportional hazards regression analyses were performed to determine independent prognostic factors for disease survival. All the variables with significant association in univariate analysis (by Kaplan-Meier with a $P$-value $<0.2)$ were included in multivariate model 
(Cox regression) to determine their independent effects. The relative risk (RR) and 95\% confidence intervals (CI) were calculated. The value of $p$ less than 0.05 was considered statistically significant. Data were analysed using the SPSS 16.0 (SPSS Inc., Chicago, Illinois) software package.

\section{ACKNOWLEDGMENTS}

This work was supported by the National Natural Science Foundation of China (No.81472197).

\section{CONFLICTS OF INTEREST}

The authors indicate no conflicts of interest.

\section{REFERENCES}

1. Torre LA, Bray F, Siegel RL, Ferlay J, Lortet-Tieulent J and Jemal A. Global cancer statistics, 2012. CA Cancer J Clin. 2015; 00:00-00.

2. Coleman RE. Metastatic bone disease: clinical features, pathophysiology and treatment strategies. Cancer Treat Rev. 2001; 27:165-176.

3. Roodman GD. Mechanisms of bone metastasis. N Engl J Med. 2004; 350:1655-1664.

4. Tsuya A, Kurata T, Tamura K and Fukuoka M. Skeletal metastases in non-small cell lung cancer: a retrospective study. Lung Cancer. 2007; 57:229-232.

5. Dunford JE, Thompson K, Coxon FP, Luckman SP, Hahn FM, Poulter CD, Ebetino FH and Rogers MJ. Structureactivity relationships for inhibition of farnesyl diphosphate synthase in vitro and inhibition of bone resorption in vivo by nitrogen-containing bisphosphonates. J Pharmacol Exp Ther. 2001; 296:235-242.

6. Lu S, Zhang J, Zhou Z, Liao ML, He WZ, Zhou XY, Li ZM, Xiang JQ, Wang JJ and Chen HQ. Synergistic inhibitory activity of zoledronate and paclitaxel on bone metastasis in nude mice. Oncol Rep. 2008; 20:581-587.

7. Ory B, Heymann MF, Kamijo A, Gouin F, Heymann D and Redini F. Zoledronic acid suppresses lung metastases and prolongs overall survival of osteosarcoma-bearing mice. Cancer. 2005; 104:2522-2529.

8. Ozturk OH, Bozcuk H, Burgucu D, Ekinci D, Ozdogan M, Akca S and Yildiz M. Cisplatin cytotoxicity is enhanced with zoledronic acid in A549 lung cancer cell line: preliminary results of an in vitro study. Cell Biol Int. 2007; 31:1069-1071.

9. Li YY, Chang JW, Chou WC, Liaw CC, Wang HM, Huang JS, Wang CH and Yeh KY. Zoledronic acid is unable to induce apoptosis, but slows tumor growth and prolongs survival for non-small-cell lung cancers. Int $\mathrm{J}$ Cancer. 2015; 136:E534-4.

10. Chang JW, Hsieh JJ, Shen YC, Yeh KY, Wang CH, Li YY and Hsu T. Bisphosphonate zoledronic acid enhances the inhibitory effects of gefitinib on EGFR-mutated non-small cell lung carcinoma cells. Cancer Lett. 2009; 278:17-26.

11. Rosen LS, Gordon D, Tchekmedyian NS, Yanagihara R, Hirsh V, Krzakowski M, Pawlicki M, De Souza P, Zheng M, Urbanowitz G, Reitsma D and Seaman J. Longterm efficacy and safety of zoledronic acid in the treatment of skeletal metastases in patients with nonsmall cell lung carcinoma and other solid tumors: a randomized, Phase III, double-blind, placebo-controlled trial. Cancer. 2004; 100:2613-2621.

12. Lopez-Olivo MA, Shah NA, Pratt G, Risser JM, Symanski E and Suarez-Almazor ME. Bisphosphonates in the treatment of patients with lung cancer and metastatic bone disease: a systematic review and meta-analysis. Support Care Cancer. 2012; 20:2985-2998.

13. Mok TS, Wu YL, Thongprasert S, Yang CH, Chu DT, Saijo N, Sunpaweravong P, Han B, Margono B, Ichinose Y, Nishiwaki Y, Ohe Y, Jin-Ji Yang, et al. Gefitinib or Carboplatin-Paclitaxel in Pulmonary Adenocarcinoma. N Engl J Med. 2009; 361:947-957.

14. Lee CK, Brown C, Gralla RJ, Hirsh V, Thongprasert S, Tsai CM, Tan EH, Ho JC, Chu da T, Zaatar A, Osorio Sanchez JA, Vu VV, Au JS, et al. Impact of EGFR inhibitor in non-small cell lung cancer on progression-free and overall survival: a meta-analysis. J Natl Cancer Inst. 2013; 105: 595-605.

15. Hendriks LE, Smit EF, Vosse BA, Mellema WW, Heideman DA, Bootsma GP, Westenend M, Pitz C, de Vries GJ, Houben R, Grunberg K, Bendek M, Speel EJ, et al. EGFR mutated non-small cell lung cancer patients: more prone to development of bone and brain metastases? Lung Cancer. 2014; 84:86-91.

16. Keizman D, Ish-Shalom M, Pili R, Hammers $H$, Eisenberger MA, Sinibaldi V, Boursi B, Maimon N, Gottfried M, Hayat H, Peer A, Kovel S, Sella A, et al. Bisphosphonates combined with sunitinib may improve the response rate, progression free survival and overall survival of patients with bone metastases from renal cell carcinoma. Eur J Cancer. 2012; 48:1031-1037.

17. Beuselinck B, Wolter P, Karadimou A, Elaidi R, Dumez H, Rogiers A, Van Cann T, Willems L, Body JJ, Berkers J, Van Poppel H, Lerut E, Debruyne P, et al. Concomitant oral tyrosine kinase inhibitors and bisphosphonates in advanced renal cell carcinoma with bone metastases. Br J Cancer. 2012; 107:1665-1671.

18. Polascik TJ. Bisphosphonates in oncology: evidence for the prevention of skeletal events in patients with bone metastases. Drug Des Devel Ther. 2009; 3:27-40.

19. Hatoum HT, Lin SJ, Guo A, Lipton A and Smith MR. Zoledronic acid therapy impacts risk and frequency of skeletal complications and follow-up duration in prostate cancer patients with bone metastasis. Curr Med Res Opin. 2011; 27:55-62.

20. Zarogoulidis K, Boutsikou E, Zarogoulidis P, Eleftheriadou E, Kontakiotis T, Lithoxopoulou H, Tzanakakis G, 
Kanakis I and Karamanos NK. The impact of zoledronic acid therapy in survival of lung cancer patients with bone metastasis. Int J Cancer. 2009; 125:1705-1709.

21. Hirsh V, Major PP, Lipton A, Cook RJ, Langer CJ, Smith MR, Brown JE and Coleman RE. Zoledronic Acid and Survival in Patients with Metastatic Bone Disease from Lung Cancer and Elevated Markers of Osteoclast Activity. J Thorac Oncol. 2008; 3:228-236.

22. Morgan GJ, Davies FE, Gregory WM, Cocks K, Bell SE, Szubert AJ, Navarro-Coy N, Drayson MT, Owen RG, Feyler S, Ashcroft AJ, Ross F, Byrne J, et al. First-line treatment with zoledronic acid as compared with clodronic acid in multiple myeloma (MRC Myeloma IX): a randomised controlled trial. Lancet. 2010; 376:1989-1999.

23. Ottewell PD, Wang N, Brown HK, Reeves KJ, Fowles CA, Croucher PI, Eaton CL and Holen I. Zoledronic Acid has differential antitumor activity in the pre- and postmenopausal bone microenvironment in vivo. Clin Cancer Res. 2014; 20:2922-2932.

24. Corey E, Brown LG, Quinn JE, Poot M, Roudier MP, Higano CS and Vessella RL. Zoledronic Acid Exhibits Inhibitory Effects on Osteoblastic and Osteolytic Metastases of Prostate Cancer. Clin Cancer Res. 2003; 9:295-306.

25. Di Salvatore M, Orlandi A, Bagala C, Quirino M, Cassano A, Astone A and Barone C. Anti-tumour and antiangiogenetic effects of zoledronic acid on human non-smallcell lung cancer cell line. Cell Prolif. 2011; 44:139-146.

26. Zhang W, Zhu XD, Sun HC, Xiong YQ, Zhuang PY, $\mathrm{Xu}$ HX, Kong LQ, Wang L, Wu WZ and Tang ZY. Depletion of tumor-associated macrophages enhances the effect of sorafenib in metastatic liver cancer models by antimetastatic and antiangiogenic effects. Clin Cancer Res. 2010; 16:3420-3430.

27. Kiper HD, Kaymaz BT, Gokbulut AA, Selvi N, Avci CB, Kosova B, Iskender G, Yandim MK, Gunduz C, Sahin F, Baran Y and Saydam G. STAT pathway in the regulation of zoledronic acid-induced apoptosis in chronic myeloid leukemia cells. Biomed Pharmacother. 2013; 67:527-532.

28. Santini D, Vincenzi B, Galluzzo S, Battistoni F, Rocci L, Venditti O, Schiavon G, Angeletti S, Uzzalli F, Caraglia M, Dicuonzo G and Tonini G. Repeated intermittent low-dose therapy with zoledronic acid induces an early, sustained, and long-lasting decrease of peripheral vascular endothelial growth factor levels in cancer patients. Clin Cancer Res. 2007; 13:4482-4486.

29. Benzaid I, Monkkonen H, Bonnelye E, Monkkonen J and Clezardin P. In vivo phosphoantigen levels in bisphosphonate-treated human breast tumors trigger Vgamma9Vdelta2 T-cell antitumor cytotoxicity through ICAM-1 engagement. Clin Cancer Res. 2012; 18:6249-6259.

30. Scagliotti GV, Kosmidis P, de Marinis F, Schreurs AJ, Albert I, Engel-Riedel W, Schallier D, Barbera S, Kuo HP, Sallo V, Perez JR and Manegold C. Zoledronic acid in patients with stage IIIA/B NSCLC: results of a randomized, phase III study. Ann Oncol. 2012; 23:2082-2087.
31. Pandya KJ, Gajra A, Warsi GM, Argonza-Aviles E, Ericson SG and Wozniak AJ. Multicenter, randomized, phase 2 study of zoledronic acid in combination with docetaxel and carboplatin in patients with unresectable stage IIIB or stage IV non-small cell lung cancer. Lung Cancer. 2010; 67:330-338.

32. Murakami H, Yamanaka T, Seto T, Sugio K, Okamoto I, Sawa T, Hirashima T, Takeda K, Atagi S, Fukuoka M, Nakanishi Y, Nakagawa K and Yamamoto N. Phase II study of zoledronic acid combined with docetaxel for non-small-cell lung cancer: West Japan Oncology Group. Cancer Sci. 2014; 105:989-995.

33. Melisi D, Caputo R, Damiano V, Bianco R, Veneziani BM, Bianco AR, De Placido S, Ciardiello F and Tortora G. Zoledronic acid cooperates with a cyclooxygenase-2 inhibitor and gefitinib in inhibiting breast and prostate cancer. Endocr Relat Cancer. 2005; 12:1051-1058.

34. Hirsch FR, Janne PA, Eberhardt WE, Cappuzzo F, Thatcher N, Pirker R, Choy H, Kim ES, Paz-Ares L, Gandara DR, Wu YL, Ahn MJ, Mitsudomi T, Shepherd FA, Mok TS. Epidermal growth factor receptor inhibition in lung cancer: status 2012. J Thorac Oncol 2013;8:373-84.

35. Sen M, Joyce S, Panahandeh M, Li C, Thomas SM, Maxwell J, Wang L, Gooding WE, Johnson DE, Grandis JR. Targeting Stat3 abrogates EGFR inhibitor resistance in cancer. Clin Cancer Res 2012;18:4986-96.

36. Lai Y, Zhang Z, Li J, Sun D, Zhou Y, Jiang T, Han Y, Huang L, Zhu Y, Li X and Yan X. EGFR mutations in surgically resected fresh specimens from 697 consecutive Chinese patients with non-small cell lung cancer and their relationships with clinical features. International journal of molecular sciences. 2013; 14:24549-24559.

37. Sharma SV, Bell DW, Settleman J and Haber DA. Epidermal growth factor receptor mutations in lung cancer. Nat Rev Cancer. 2007; 7:169-181.

38. Mitsudomi T, Kosaka T, Endoh H, Horio Y, Hida T, Mori S, Hatooka S, Shinoda M, Takahashi T and Yatabe Y. Mutations of the epidermal growth factor receptor gene predict prolonged survival after gefitinib treatment in patients with non-small-cell lung cancer with postoperative recurrence. J Clin Oncol. 2005; 23:2513-2520.

39. Riely GJ, Pao W, Pham D, Li AR, Rizvi N, Venkatraman ES, Zakowski MF, Kris MG, Ladanyi M and Miller VA. Clinical course of patients with non-small cell lung cancer and epidermal growth factor receptor exon 19 and exon 21 mutations treated with gefitinib or erlotinib. Clin Cancer Res. 2006; 12:839-844.

40. Shukuya T, Takahashi T, Kaira R, Ono A, Nakamura Y, Tsuya A, Kenmotsu H, Naito T, Kaira K, Murakami H, Endo M, Takahashi K and Yamamoto N. Efficacy of gefitinib for non-adenocarcinoma non-small-cell lung cancer patients harboring epidermal growth factor receptor mutations: a pooled analysis of published reports. Cancer Sci. 2011; 102:1032-1037. 